\title{
Textbook descriptions of disease - where's the beef?
}

A resident asks you, the attending physician in an emergency department, to see a 68 year old woman with severe pain in her chest. The pain's location (retrosternal, radiating through to her back), quality ("tearing"), and onset (sudden, not crescendo) prompted the resident to think of acute aortic dissection along with other causes of chest pain; however, because the examination shows symmetric pulses in her arms, the resident dismisses dissection and plans no test to exclude it. You recall that pulse asymmetry may not occur in some patients with dissection, but you cannot recall the proportion. Nevertheless, you suggest that the absence of this finding should not be used to exclude dissection, and you decide with the resident to order further testing for this condition. To refresh your memory and teach the resident when to pursue this diagnosis, you seek information on how frequently patients with dissection have asymmetric pulses. In a textbook description of aortic dissection, you find only one sentence about this: "A pulse discrepancy between arms may indicate compromise of the aortic arch vessels".

Clinicians who practise and teach evidence-based medicine are by now familiar with some limitations of textbooks. The usual beef with textbooks is that their treatment recommendations are out of date. ${ }^{2}$ The above scenario illustrates another complaint - that textbook descriptions of disease often omit information about the frequency and temporal characteristics of clinical manifestations in patients with the disorder, even when good evidence from clinical care research exists. ${ }^{3-5}$ When one textbook came up short, we looked at several others; the table shows what we did and did not find..$^{6-16}$ This omission of quantitative information from textbook descriptions of disease clearly reduces their usefulness for clinical diagnosis.

Evidence about the frequency of clinical manifestations of disease can come from clinical care research studies, wherein investigators begin by assembling a sample of patients believed to have the disorder, determine the presence or absence of each finding in each patient, and then report the yield of this evaluation. The main results of such studies are often shown in a table listing the clinical findings along with the number and percentage of patients who have each finding. Patients usually have more than one finding, so the percentages are not mutually exclusive. Details of the qualitative features, temporal characteristics, and clusters or patterns of findings may also be described. Because these studies can vary in the rigour of the methods used, they should be critically appraised for validity, importance, and applicability. ${ }^{17}$ For validity, 4 issues are important: how the diagnoses were verified, how the study samples relate to all patients with the disease, how the clinical findings were sought, and how the clinical findings were characterised. ${ }^{17}$

How might the inclusion of this evidence make textbook descriptions of disease more useful to clinicians? Recall that in the scenario the resident had initially considered aortic dissection as a possible cause of the patient's pain but discarded the hypothesis because the patient's pulses were symmetric. Yet in studies of patients with proven aortic dissection, abnormal pulses have been found in only a few patients, ranging from $6 \%$ to $34 \% .^{3-5}$ In other words, the pulses were normal in $66 \%$ to $94 \%$ of patients with aortic dissection. If we use the absence of pulse asymmetry to rule out aortic dissection, we would miss the diagnosis $66 \%$ to $94 \%$ of the time! Textbook descriptions that included the frequency of pulse abnormalities and other findings in aortic dissection could help the resident avoid prematurely discarding this diagnostic hypothesis.

Each clinical manifestation of a disease can be thought of as a "test" for the presence of that disease. Viewed this way, the frequency of each clinical manifestation in patients with the disease is equivalent to the sensitivity of that finding - that is, how frequently the "test" is positive in patients with the disorder. Findings that occur in less than $100 \%$ of patients thus have diagnostic sensitivities less than $100 \%$, so we should not use their absence to exclude the disorder. Keep in mind that evidence on the frequency of clinical manifestations in one disease seldom includes the frequency of these same findings in other diseases. Given this, neither the specificity of the findings

Was the frequency of pulse abnormality in aortic dissection provided in these textbooks?*

\begin{tabular}{|c|c|c|c|c|}
\hline Textbookst & $\begin{array}{l}\text { Text mentions pulse } \\
\text { abnormalities in aortic } \\
\text { dissection }\end{array}$ & $\begin{array}{l}\text { Text gives frequency of } \\
\text { pulse abnormalities in } \\
\text { aortic dissection }\end{array}$ & $\begin{array}{l}\text { Text gives frequency of any } \\
\text { other clinical findings in aortic } \\
\text { dissection }\end{array}$ & $\begin{array}{l}\text { Text references quantitative studies } \\
\text { of the frequency of clinical findings } \\
\text { in aortic dissection }\end{array}$ \\
\hline Ball $^{6}$ & Yes & Yes & Yes & Yes \\
\hline Barker $^{7}$ & Yes & No & No & No \\
\hline Cecils $^{8}$ & Yes & No & Yes & No \\
\hline Goroll $^{9}$ & Yes & No & Yes & No \\
\hline Harrison's ${ }^{10}$ & Yes & No & No & Yes \\
\hline Kelley ${ }^{11}$ & Yes & No & No & No \\
\hline $\mathrm{McGee}^{12}$ & Yes & Yes & Yes & Yes \\
\hline Noble $^{13}$ & Yes & No & No & No \\
\hline Oxford ${ }^{14}$ & Yes & Yes & No & No \\
\hline$S A M^{15}$ & Yes & Yes & Yes & Yes \\
\hline Stein $^{1}$ & Yes & No & No & No \\
\hline UpToDate $^{16}$ & Yes & No & Yes & Yes \\
\hline
\end{tabular}

"Yes" indicates that the text cites at least one such study. None of these texts cites all 3 studies we found, ${ }^{3-5}$ and none presents a critical appraisal or a quantitative compilation of this evidence. †Textbooks are listed alphabetically. Those in italics are listed by their widely used short titles, whereas those in plain text are listed by the last name of the first or only editor. 
nor their likelihood ratios can be estimated, so by itself this evidence won't be sufficient to guide the revision of our diagnostic probabilities. ${ }^{17}$

Nevertheless, evidence about the frequency of clinical manifestations can help us overcome some of the limitations of our own experience. As we care for and diagnose patients, we store them in our memories as instances of disease, in a kind of case library ${ }^{18}{ }^{19}$ We can draw on these remembered cases when we consider the illnesses of subsequent patients and decide how to classify them into diagnoses. ${ }^{18-20}$ If our case numbers were truly vast (hundreds, if not thousands), if the spectrum of disease we had seen was sufficiently wide and representative, if we had used diagnostic criteria consistently over time, if we had searched for each clinical finding equally diligently in every patient, and if our memories were perfect, then perhaps our library of remembered cases would allow us to accurately estimate the frequencies of clinical manifestations of that disease and interpret them properly.

However, for many diseases, the actual number of patients we've seen with that diagnosis is small, and we may not have been consistent in our clinical examinations or in our use of diagnostic criteria over time. Furthermore, the referral patterns by which patients come to our practices can selectively narrow the spectrum of patients with a given disease that we see. ${ }^{21}$ And who among us has a perfect memory? Thus, we are prone to error in estimating the frequency of clinical manifestations of many diseases and in interpreting their presence or absence in our patients' illnesses. As shown above, such errors can lead us to incorrect diagnostic closure by prematurely excluding hypotheses. ${ }^{22}$

At present, because many textbooks omit information about the frequency of clinical manifestations, clinicians who want to use this evidence for clinical diagnosis often have to pursue it in the medical literature. Because busy clinicians lack the time to search for this information for every patient, how can we decide when it matters most to review this knowledge? Observations of our own and others' learning needs suggest that we should review evidence about the frequency of clinical manifestations in the following situations: when encountering patients with atypical presentation of disorders we see frequently; when making the diagnosis of any condition we see less frequently or know less well; when the definitions of a disease or its diagnostic criteria are changed; when important new research about the frequency of clinical manifestations is published; and when teaching others about the diagnosis of a condition.

As we find, appraise, and use good evidence about the clinical manifestations of diseases, it should help us to interpret more accurately the clinical findings in our patients and help us to reduce diagnostic error. As the table shows, some texts are slim on the evidence, whereas others are more nourishing. We have a recurring dream that one day all textbook descriptions of disease will be based on high quality clinical care research into the clinical features of disease. Some texts, particularly newer ones, have taken up the challenge; for the others, we continue to ask, "Where's the beef?"

While this editorial was in press, a systematic review was published on the accuracy of clinical findings for the diagnosis of aortic dissection. ${ }^{23}$ The reviewers estimated the pooled sensitivity for pulse deficit to be $31 \%$ (95\% CI, 24\% to 39\%). It will be interesting to see which texts report this finding and how soon they do so.

W SCOTT RICHARDSON, MD
Wright State University
Dayton, Ohio, USA
MARK C WILSON, MD, MPH
Wake Forest University
Winstom-Salem, North Carolina, USA

1 Zabalgoitia M, O'Rourke RA. Diseases of the aorta. In: Stein JH, editor. Internal medicine. 5th edition. St. Louis: Mosby, 1998:299-304.

2 Antman EM, Lau J, Kupelnick B, et al. A comparison of results of meta-analyses of randomized control trials and recommendations of clinical experts. JAMA 1992;268:240-8.

3 Slater EE, DeSanctis RW. The clinical recognition of dissecting aortic aneurysm. Am J Med 1976;60:625-33.

4 Spittell PC, Spittell JA Jr, Joyce JW, et al. Clinical features and differential diagnosis of aortic dissection: experience with 236 cases (1980 through 1990). Mayo Clin Proc 1993;68:642-51.

5 Hagan PG, Nienaber CA, Isselbacher EM, et al. The International Registry of Acute Aortic Dissection (IRAD): new insights into an old disease. JAMA 2000;283:897-903.

6 Ball CM, Phillips RS. Evidence-based on call: acute medicine. Edinburgh: Churchill-Livingstone, 2001.

7 Barker LR. Hypertension. In: Barker LR, Burton JR, Zieve PD, editors. Principles of ambulatory medicine. 5th edition. Baltimore: Williams \& Wilkins, 1999:852.

8 Isselbacher EM. Diseases of the aorta. In: Goldman L, Bennett JC, editors. Cecil textbook of medicine. 21st edition. Philadelphia: WB Saunders, 2000:353-7.

9 Goroll AH. Evaluation of chest pain. In: Goroll AH, Mulley AG, editors Primary care medicine. 4th edition. Philadelphia: Lippincott, Williams \& Wilkins, 2000:108-9

10 Dzau VJ, Creager MA. Diseases of the aorta. In: Braunwald E, Fauci AS Kasper DL, et al, editors. Harrison's principles of internal medicine. 15th edition. New York: McGraw-Hill, 2001:1431-4.

11 Williams ES. Approach to the patient with chest pain. In: Kelley WN, editor. Textbook of internal medicine. 3rd edition. Philadelphia: LippincottRaven, 1997:317-22.

12 McGee S. Evidence-based physical diagnosis. Philadelphia: WB Saunders, 2001.

13 Lilly LS. Ischemic heart disease. In: Noble J, editor. Textbook of primary care medicine. 3rd edition. St. Louis: Mosby, 2001:545-70.

14 Sleight P. Myocardial infarction. In: Weatherall DJ, Ledingham JG, Warrell DA, editors. Oxford textbook of medicine. 3rd edition. Oxford: Oxford University Press, 1996:2331-49.

15 Eagle KA, Armstrong WF. Diseases of the aorta. In: Dale DC, editor WebMD Scientific American Medicine - CD connected, WebMD Corp; October 2001 [accessed 28 Dec 2001].

16 Manning WJ. Clinical manifestations and diagnosis of aortic dissection. In: Rose BD, editor. UpToDate. Wellesley, MA: UpToDate Inc, 2001 (www.uptodate.com).

17 Richardson WS, Wilson MC, Williams JW Jr, et al. Users' guides to the medical literature: XXIV. How to use an article on the clinical manifestations of disease. Evidence-Based Medicine Working Group. JAMA 2000;284:869-75.

18 Schmidt HG, Norman GR, Boshuizen HP. A cognitive perspective on medical expertise: theory and implication. Acad Med 1990;65: 611-21.

19 Regehr G, Norman GR. Issues in cognitive psychology: implications for professional education. Acad Med 1996;71:988-1001.

20 Wulff HR, Gotzsche PC. Rational diagnosis and treatment: evidence-based clinical decision-making. 3rd edition. Oxford: Blackwell Scientific, 2000.

21 Ransohoff DF, Feinstein AR. Problems of spectrum and bias in evaluating the efficacy of diagnostic tests. N Engl J Med 1978;299:926-30.

22 Kassirer JP, Kopelman RI. Cognitive errors in diagnosis: instantiation, classification, and consequences. Am J Med 1989;86:433-41.

23 Klompas M. Does this patient have an acute thoracic aortic dissection? JAMA 2002;287:2262-72. 


\begin{tabular}{|c|c|c|c|}
\hline Acta Obstet Gynecol Scand & Arch Pediatr Adolesc Med & Gut & J Vasc Surg \\
\hline Age Ageing & Arch Surg & Heart & Lancet \\
\hline Am J Cardiol & Arthritis Rheum & Hypertension & Med Care \\
\hline Am J Med & BJOG & JAMA & Med J Aust \\
\hline Am J Obstet Gynecol & BMJ & J Am Coll Cardiol & N Engl J Med \\
\hline Am J Psychiatry & Br J Gen Pract & J Am Coll Surg & Neurology \\
\hline Am J Public Health & BrJ Psychiatry & J Am Geriatr Soc & Obstet Gynecol \\
\hline Am J Respir Crit Care Med & BrJ Surg & J Clin Epidemiol & Pain \\
\hline Ann Emerg Med & СMAJ & J Fam Pract & Pediatrics \\
\hline Ann Intern Med & Chest & J Gen Intern Med & Rheumatology \\
\hline Ann Surg & Circulation & $\mathrm{J}$ Infect Dis & Spine \\
\hline Arch Dis Child & Cochrane Library & J Intern Med & Stroke \\
\hline Arch Gen Psychiatry & Crit Care Med & J Neurol Neurosurg Psychiatry & Surgery \\
\hline Arch Intern Med & Diabetes Care & J Pediatr & Thorax \\
\hline Arch Neurol & Gastroenterology & & \\
\hline
\end{tabular}

How to cite material from Evidence-Based Medicine

Citation of material from the Notebook

Milne R, Hicks N. Evidence-based purchasing [EBM Note]. Evidence-Based Medicine 1996 May-Jun;1:101-2.

Citation for material taken from a structured abstract, written without attribution by a staff member

Antihypertensive drugs decrease mortality, coronary events, and stroke in elderly persons [abstract]. Evidence-Based Medicine 1996 May-Jun;4:105. Abstract of: Pearce KA, Furberg CD, Rushing J. Does antihypertensive treatment of the elderly prevent cardiovascular events or prolong life? A meta-analysis of hypertension treatment trials. Arch Fam Med 1995;4:943-50.

Citation for material taken from a commentary to an article

Olds D. Commentary on "Home visiting programmes reduce childhood injury." Evidence-Based Medicine 1996 May-Jun;4:112. Comment on: Roberts I, Kramer MS, Suissa S. Does home visiting prevent childhood injury? A systematic review of randomised controlled trials. BMJ 1996;312:29-33.

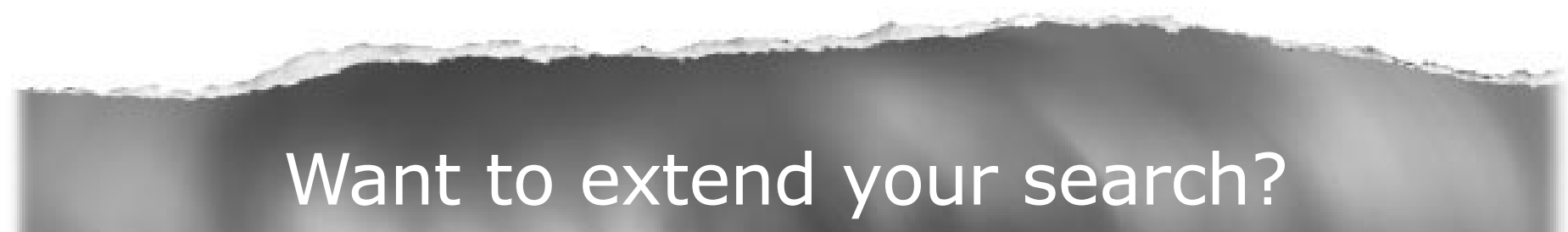

Cross journal searching

If you can't find what you are looking for in Evidence-Based Medicine you can extend your search across many of the more than 300 journals available for selection. You can restrict your search to specific subject areas (eg, clinical psychiatry, basic research), or select specific journals, or search all available titles. 